\title{
PERANCANGAN APLIKASI POINT OF SALE BERBASIS WEB PADA TOKO PROJECT SALFA TARAKAN
}

\author{
Suprianto $\oplus^{1)}$, Muhammad Fadlan $\oplus^{2)}$, dan Denis Prayogi $\oplus^{3)}$ \\ ${ }^{1}$ Manajemen Informatika, STMIK PPKIA Tarakanita Rahmawati \\ ${ }^{2}$ Sistem Informasi, STMIK PPKIA Tarakanita Rahmawati \\ ${ }^{3}$ Teknik Informatika, STMIK PPKIA Tarakanita Rahmawati \\ ${ }_{1,2,3} \mathrm{Jl}$. Yos Sudarso 8 Tarakan Barat, Tarakan, 77111 \\ E-mail : suprianto@ppkia.ac.id ${ }^{1)}$, fadlan@ppkia.ac.id ${ }^{2)}$,denis@ppkia.ac.id ${ }^{3)}$
}

\begin{abstract}
ABSTRAK
Aplikasi Point of Sale yang biasa disebut POS merupakan aplikasi yang dapat membantu proses transaksi penjualan seperti pada toko yang umumnya terjadi kegiatan jual beli. Toko Project Salfa yang bergerak di bidang penjualan dan penyedia jasa saat ini masih menggunakan pencatatan manual di setiap transaksi sehingga menyulitkan pemilik ketika akan melakukan rekapitulasi terkait laporan penjualan maupun pemasukan. Penelitian ini membuat aplikasi POS berdasarkan kebutuhan dari pemilik toko dengan menggunakan model Waterfall sebagai perancangan dan pengembangan aplikasinya. Dari penerapan model Waterfall, dapat dihasilkan aplikasi yang memiliki fitur-fitur yang sesuai dengan kebutuhan pemilik toko seperti dapat melakukan pendataan barang, member, seller, transaksi penjualan, pengeluaran serta laporan-laporan dari transaksi tersebut yang dicatat dalam bentuk kas di aplikasi POS. aplikasi dibuat berbasis web agar memudahkan pengembangan ke depannya dengan menggunakan bahasa pemrograman PHP (Hypertext Pre-processor) dan database berbasis jaringan seperti MySQL (My Structure Query Language).
\end{abstract}

Kata Kunci: Point Of Sale, Web, Project Salfa, Waterfall, PHP, MySQL.

\section{PENDAHULUAN}

Saat ini teknologi sudah menjadi kebutuhan yang cukup penting dalam membantu pekerjaan-pekerjaan di berbagai bidang. Salah satu hasil dari kemajuan teknologi adalah di bidang ekonomi dan bisnis. Bisnis yang semula dilakukan dengan cara-cara konvensional dapat berubah dengan kehadiran teknologi informasi (Akhmad \& Purnomo, 2021) dan dapat memberikan nilai tambah serta keunggulan dari bisnis yang dijalankan (Sugumonrong, dkk, 2019). Makin banyaknya penggunaan teknologi berdampak tumbuhnya berbagai macam kemajuan, diantaranya marketplace dan toko yang menjual barang berbasis website sehingga penjualan dapat meningkat dan tidak hanya terbatas pada penjualan di sekitar area yang dekat saja.

Project Salfa merupakan sebuah toko yang bergerak di bidang penjualan produk kerajinan tangan dan jasa Party Planner, Gift Shop dan Wedding Equipment skala Usaha Mikro, Kecil dan Menengah (UMKM) yang berada di Tarakan tepatnya Jalan Imam Bonjol Kelurahan Pamusian Kecamatan Tarakan Tengah. Project Salfa mengerjakan berbagai kerajinan seperti dekorasi acara, penyewaan peralatan pesta serta penjualan kerajinan tangan lainnya seperti bucket, kado, mahar, papan ucapan dan lainnya.

Banyaknya produk yang dihasilkan pada toko Project Salfa membuat pemilik mengalami kesulitan dalam melakukan pendataan barang, baik berupa penjualan barang maupun pemesanan seperti dekorasi dan lainnya. Kesulitan lain yang dialami pemilik yaitu tentang pemasukan dan pengeluaran toko yang tercatat secara manual menggunakan program Microsoft Excel apabila ada penjualan dan pemesanan. Pencatatan manual membutuhkan waktu yang cukup lama dan tidak efektif, kesalahan informasi yang mungkin terjadi, seperti pencatatan rugi laba dan barang (Marisa \& Yuarita, 2017) serta kesulitan dalam mencatat transaksi penjualan, manajemen pengecekan toko dan pembayaran (Wiguna, dkk, 2019).

Pemilik membutuhkan sebuah aplikasi yang dapat membantu pekerjaan di toko project salfa, seperti pendataan barang, pemesanan barang atau jasa, penjualan barang berbasis point of sale serta pencatatan pengeluaran yang berkaitan dengan operasional dan modal sehingga setiap bulan dapat dilaporkan pendapatan kotor, pendapatan bersih serta jumlah pengeluaran.

Penelitian yang sebelumnya dilakukan Muhammad Sony Maulana yang berjudul "Rancangan dan Implementasi Aplikasi Web Point of Sales pada Butik Anak Galer Freya" menghasilkan aplikasi berbasis web yang diuji coba menggunakan metode Black-Box dan dapat memenuhi kebutuhan dari pemiliknya (Maulana, 2017). Yogo Afrianto, Novita Br Ginting, Suratun, Yashintya Nelawati meneliti tentang aplikasi POS berjudul "Sistem Informasi Inventory P.O.S (Point of 
Sales) Berbasis Web pada Counter Cellular" menghasilkan aplikasi POS yang diuji menggunakan metode Black-Box memiliki kinerja yang baik dan sesuai dengan kebutuhan pemilik konter (Afrianto, dkk, 2020). Yefta Christian dan Kelvin meneliti dengan judul "Perancangan dan Penerapan Sistem POS (Point Of Sale) Berbasis Web pada Warung Zikry" menghasilkan aplikasi bernama "SiKasir" yang memberikan dampak positif kepada pemilik seperti kemudahan dalam pengisian ulang stok barang karena dapat langsung memantau jumlah persediaan barang (Christian, 2021). Gilang Pamungkas dan Herman Yuliansyah meniliti "Rancang Bangun Aplikasi Android POS (Point Of Sale) Kafe untuk Kasir portable dan Bluetooth Printer" menghasilkan aplikasi kasir portabel berbasis Android yang dapat langsung digunakan membantu proses transaksi penjualan dan rekapitulasi laporan data transaksi (Pamungkas \& Yuliansyah, 2017).

Berdasarkan hal yang telah diuraikan dan penelitian yang dilakukan sebelumnya, maka dibutuhkan aplikasi yang dapat mengatasi masalah tersebut sehingga memudahkan pemilik dalam pekerjaannya. Aplikasi yang dibuat menggunakan Bahasa pemrograman PHP (Hypertext Pre-processor) dengan database MySQL sehingga aplikasi dapat diakses dengan mudah menggunakan browsers seperti Mozilla Firefox, Google Chrome dan lainnya.

\section{RUANG LINGKUP}

Agar penelitian tidak meluas, maka ruang lingkup penelitian ini adalah:

1. Cakupan permasalahan.

Banyaknya produk dan transaksi yang terjadi pada toko Project Salfa membuat pemilik kesulitan dalam melakukan pendataan barang, penjualan maupun pesanan dari pelanggan.

2. Batasan-batasan penelitian.

Batasan pada penelitian ini adalah pembuatan aplikasi POS berbasis web dengan fitur pendataan barang, member, reseller, transaksi penjualan, dan pencatatan kas toko.

\section{BAHAN DAN METODE}

Penelitian ini menggunakan bahan dan metode pendukung untuk menyelesaikan permasalahan yang ada. Beberapa bahan dan metode adalah:

\subsection{Aplikasi Point of Sale}

Point of Sale adalah sistem yang memungkinkan diadakannya proses transaksi penjualan seperti penjualan di toko, hotel, restoran, supermarket dan toko-toko retail. POS juga diartikan sebagai pelayanan transaksi dalam toko retail yang di dalamnya termasuk penggunaan mesin kasir (Wahyudi, dkk, 2018) Poin of Sale terdiri dari perangkat lunak (Software) yang merupakan komponen utama dalam menjalankan proses dan perangkat keras (Hardware) sebagai penunjang aplikasi yang berjalan seperti transaksi yang membutuhkan pembacaan barcode dan pencetakan nota belanja pelanggan (Wiguna, dkk, 2019). Sistem POS didesain dengan kebutuhan pelanggan (Alexander, 2020) karena terdapat beberapa kebutuhan berbeda dari setiap bidang yang menggunakan aplikasi POS.

Cara kerja sistem POS minimal bisa melakukan:

1. Mengotomatiskan proses seperti transaksi penjualan.

2. Melacak data penjualan.

3. Mengumpulkan informasi penjualan selama periode tertentu.

4. Memantau inventaris barang dan stok.

5. Dapat bekerja di jaringan komputer sehingga transaksi terkait barang dan penjualan dapat dilakukan di tempat yang berbeda.

6. Dapat melakukan multi payment atau pembayaran dengan berbagai metode seperti cash, kartu kredit, debet dan transfer.

\subsection{Web Server}

Web biasa disebut World Wide Web adalah informasi yang ditampilkan dalam bentuk teks, gambar, suara dan lainnya yang tersimpan $\mathrm{di}$ internet web server (Sugumonrong, dkk, 2019) dan diakses melalui aplikasi browser seperti Google Chrome dan Mozilla Firefox. Web server digunakan untuk menampilkan halaman dari suatu situs melalui aplikasi web browser dari client (Subekti, dkk, 2019) kepada server melalui protokol Hypertext Transfer Protokol yang berjalan di atas protokol TCP (Transfer Control Protokol) atau Internet Protocol (Arman, 2019).

\subsection{Database MySQL}

MySQL merupakan singkatan dari My Structure Query Language merupakan sistem basis data relation yang bekerja secara cepat dan mudah digunakan. Database dapat diakses secara jaringan dan bisa digunakan untuk aplikasi multi user atau banyak pengguna (Nugraha, 2021).

Keunggulan MySQL sebagai database berbasis jaringan dan multi user (Wiguna, dkk, 2019):

1. Kemudahan dalam menggunakan dengan performa tinggi.

2. Mendukung bahasa query MySQL dan dapat diakses menggunakan aplikasi ODBC (Open Database Connectivity).

3. Mampu terhubung dengan banyak Client pada waktu yang bersamaan.

\subsection{PHP}

PHP singkatan dari Hypertext Pre-processor merupakan pemrograman server side yang pemrosesan data berada di sisi server. PHP berfungsi membangun website untuk melakukan pengolahan data pada database (Nugraha, 2021).

\subsection{Metode Air Terjun}

Dalam membangun aplikasi POS untuk toko project Salfa, digunakan sebuah metode yaitu Model air terjun 
atau biasa disebut dengan Model Waterfall. Model ini sering disebut model konvensional atau classic life cycle atau merupakan salah satu model SDLC (System Development Life Cycle) yang digunakan untuk mengembangkan sistem informasi. Model ini menyediakan pendekatan alur perangkat lunak secara terurut dari analisis, desain, mengodekan serta pengujian (Handrianto \& Sanjaya, 2020). Adapun alur dapat dilihat pada gambar 1 .

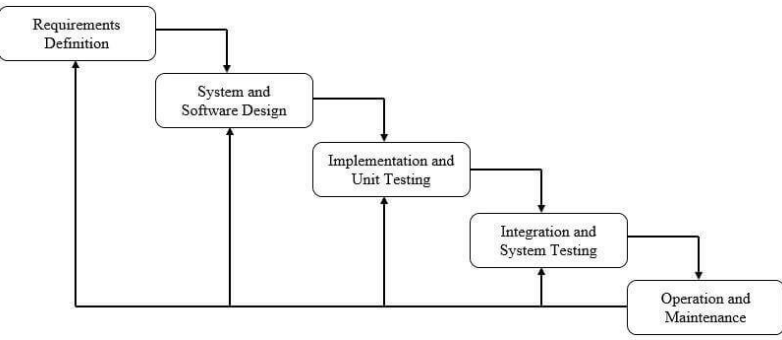

Gambar 1. Gambaran Sistem

Berdasarkan pada gambar 1, terdapat 6 tahapan dalam pembuatan aplikasi. Berikut ini penjelasan tahapan sesuai dengan model waterfall.

1. Requirements Definition

Pada tahap ini, dilakukan wawancara langsung kepada pemilik toko guna mendapatkan informasi terkait proses yang berjalan. Pada tahap ini juga dilakukan pengumpulan literatur-literatur sebagai bahan referensi dalam pembuatan aplikasi.

2. System and Software Design

Pada tahap ini dilakukan perancangan aplikasi berdasarkan literatur yang ada dan disesuaikan dengan kebutuhan dari pemilik. Perancangan aplikasi melibatkan identifikasi abstraksi dasar dari perangkat lunak dan hubungannya.

3. Implementation and Unit Testing

Pada tahap ini, penerapan rancangan dan model yang telah dibuat sebelumnya ke dalam bentuk program kecil yang disebut unit, kemudian disatukan dalam tahap kegiatan berikutnya (Ardiansyah, 2019). Setiap penerapan dan fitur-fitur sesuai kebutuhan ketika selesai dilakukan uji coba dan evaluasi terkait fungsional sehingga jika terjadi error tidak sesuai dengan kebutuhan maka segera untuk dilakukan perbaikan.

4. Integration and System Testing

Pada tahap ini, dilakukan integrasi yaitu membuat aplikasi menjadi siap pakai dimana fitur-fitur yang sebelumnya terpisah sudah menu-menu untuk mengaksesnya. Pada tahap ini juga dilakukan proses uji coba dengan mengenalkan fitur kepada pemilik toko tentang bagaimana menjalakan aplikasi secara baik dan benar.

5. Operation and Maintenance

Pada tahap ini, aplikasi telah selesai dibuat dan diserahkan kepada pemilik toko untuk digunakan. Pada tahap ini juga dibutuhkan juga terkait perawatan aplikasi terkait update dan perbaikan bug jika terjadi kendala pada saat aplikasi sudah digunakan secara terus menerus oleh pemilik toko.

\section{PEMBAHASAN}

Aplikasi POS yang dibangun dengan memanfaatkan database MySQL serta pemrograman PHP menghasilkan aplikasi yang siap digunakan dan di integrasikan dengan perangkat keras berupa komputer, barcode scanner dan printer thermal untuk pencetakan nota pelanggan. Berikut ini pembahasan dari penelitian ini.

\subsection{Analisis Kebutuhan}

1. Kebutuhan Perangkat Lunak

Berdasarkan wawancara dengan pemilik toko, maka terdapat beberapa kebutuhan fungsional yang dapat dilihat pada tabel 1 .

Tabel 1. Rancangan Kebutuhan Sistem perangkat lunak

\begin{tabular}{|c|c|c|}
\hline No & $\begin{array}{l}\text { Kebutuhan } \\
\text { Sistem }\end{array}$ & Deskripsi \\
\hline 1 & Beranda & $\begin{array}{lr}\text { Kebutuhan untuk menampilkan } \\
\text { secara singkat } & \text { informasi } \\
\text { mengenai data barang } & \end{array}$ \\
\hline 2 & Master Data & $\begin{array}{l}\text { Kebutuhan untuk mendata terkait } \\
\text { barang, kategori barang, katalog } \\
\text { harga, data member, data reseller, } \\
\text { data bank, data kas toko dan data } \\
\text { user }\end{array}$ \\
\hline 3 & Jasa & $\begin{array}{l}\text { Kebutuhan untuk mendata } \\
\text { transaksi yang berkaitan dengan } \\
\text { bidang jasa seperti dekorasi, } \\
\text { pembuatan frame, bucket, } \\
\text { selempang dan produk custom } \\
\text { sesuai dengan pesanan pelanggan }\end{array}$ \\
\hline 4 & Transaksi & $\begin{array}{l}\text { Kebutuhan untuk mendata setiap } \\
\text { transaksi penjualan barang pada } \\
\text { toko, penyewaan barang, } \\
\text { pengeluaran toko, retur reseller, } \\
\text { cash bon karyawan dan mutasi } \\
\text { pada rekening bank. }\end{array}$ \\
\hline 5 & Laporan & $\begin{array}{l}\text { Kebutuhan untuk melihat laporan } \\
\text { dari transaksi yang ada pada toko }\end{array}$ \\
\hline 6 & Pengaturan & $\begin{array}{lrr}\text { Kebutuhan untuk melakukan } \\
\text { pengaturan } & \text { pada } & \text { toko } \\
\text { menggunakan aplikasi } & \text { seperti } \\
\text { manajemen pengguna. } & \end{array}$ \\
\hline 7 & $\begin{array}{l}\text { Proses } \\
\text { Login }\end{array}$ & $\begin{array}{l}\text { Kebutuhan untuk penggunaan } \\
\text { aplikasi berdasarkan level user, } \\
\text { dimana terdapat administrator } \\
\text { yang mengelola data dan client- } \\
\text { client yang terhubung untuk } \\
\text { melakukan transaksi dengan } \\
\text { konsumen. }\end{array}$ \\
\hline
\end{tabular}

2. Kebutuhan Perangkat Keras

Aplikasi POS membutuhkan perangkat keras untuk menjalankan aplikasi utama. Spesifikasi dari perangkat keras dapat dilihat pada tabel 2. 
Tabel 2. Kebutuhan Perangkat Keras

\begin{tabular}{|l|l|l|}
\hline No & $\begin{array}{c}\text { Nama } \\
\text { Perangkat }\end{array}$ & \multicolumn{1}{c|}{ Spesifikasi } \\
\hline 1 & $\begin{array}{l}\text { Komputer } \\
\text { Server }\end{array}$ & $\begin{array}{l}\text { Prosessor Core 2 duo } \\
\text { RAM minimal 2 GB } \\
\text { Hard disk / SSD 240 GB }\end{array}$ \\
\hline 2 & $\begin{array}{l}\text { Komputer } \\
\text { Client }\end{array}$ & $\begin{array}{l}\text { Prosessor Celeron } \\
\text { RAM minimal 2 GB } \\
\text { Hard disk / SSD 120 GB }\end{array}$ \\
\hline 3 & $\begin{array}{l}\text { Decode 1 dan 2 Dimensi } \\
\text { Fitur Auto scan, Continuous } \\
\text { Pembacaan jarak barcode hingga } \\
\text { 60 cm } \\
\text { Pola scan berbasis } \text { Imager }\end{array}$ \\
\hline 4 & $\begin{array}{l}\text { Printer } \\
\text { Thermal }\end{array}$ & $\begin{array}{l}\text { Interface USB } \\
\text { Metode Print Direct Thermal } \\
\text { Fitur Auto cutter } \\
\text { Kecepatan print 200mm/s }\end{array}$ \\
\hline 5 & Switch & 8 Port Gigabit Ethernet \\
\hline
\end{tabular}

\subsection{Desain Sistem}

1. Use Case Diagram

Desain dari sistem terdiri dari dua pemodelan menggunakan use case diagram dan activity diagram. Use case diagram pada gambar 2 memperlihatkan unit-unit yang terkait pada aplikasi.

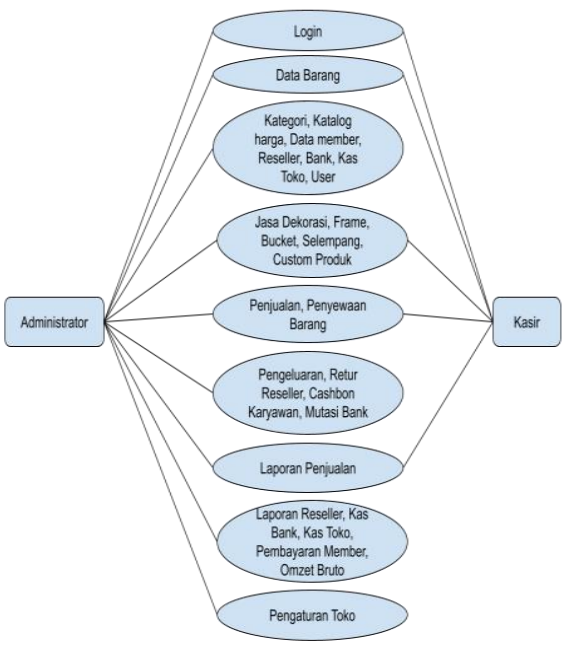

\section{Gambar 2. Use Case Diagram Perancangan Aplikasi POS}

Pada gambar 2, dapat dilihat akses dari administrator dan kasir. Semua fitur dapat di akses oleh administrator atau dalam penelitian ini adalah pemilik dari toko. Sedangkan kasir merupakan karyawan yang dapat melakukan transaksi penjualan dan pemesanan jasa dari pelanggan. Unit kasir terdiri dari beberapa host yang terhubung ke dalam jaringan yang sama sehingga masing-masing kasir dapat melakukan transaksi terkait penjualan.

2. Activity Diagram

Activity Diagram menggambarkan alur kerja dan urutan aktivitas dari suatu proses. Pada aplikasi POS ini activity diagram dapat dilihat pada gambar 3 .

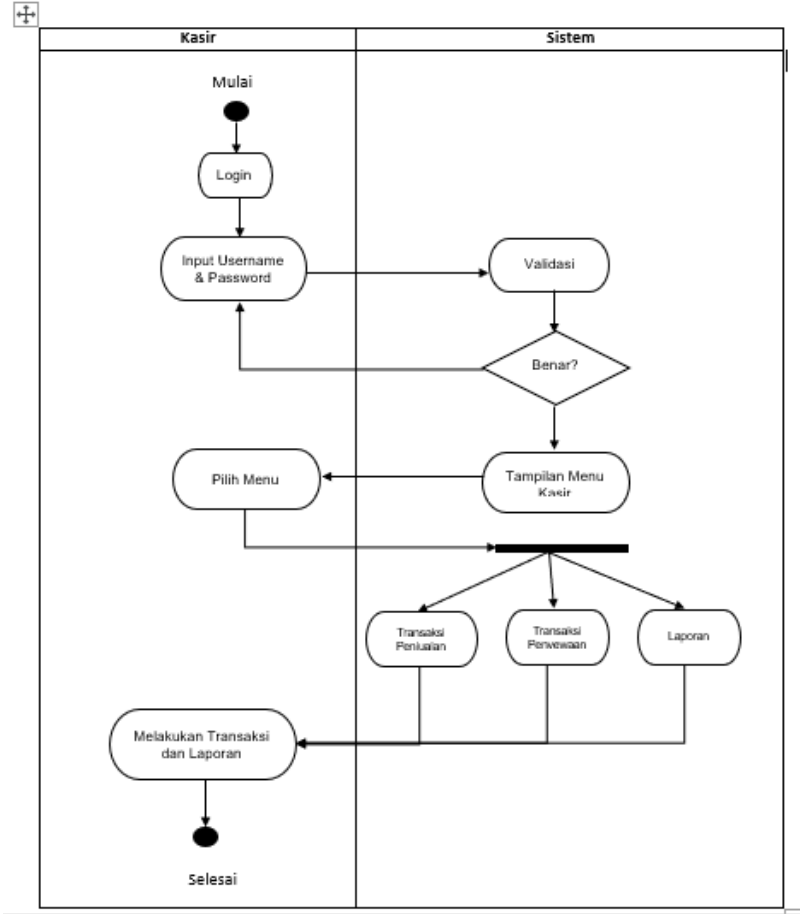

Gambar 3. Activity Diagram

Activity Diagram pada gambar 3 menunjukkan alur aktivitas pada pengguna dengan hak akses kasir yang bertugas melakukan input transaksi penjualan dan penyewaan barang pada toko.

\subsection{Implementasi Sistem}

1. Form Login Aplikasi POS

Form login digunakan untuk masuk ke dalam sistem aplikasi Pos. kategori level user yang terdapat ada dua sesuai dengan kebutuhan yaitu level administrator dan level kasir. Form login dapat dilihat pada gambar 4.

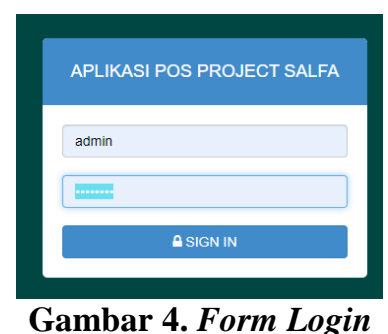

User administrator digunakan untuk melakukan akses penuh seperti mendata, mengubah dan menghapus data. Sedangkan user kasir hanya akses ke aplikasi utama POS yaitu transaksi penjualan, jasa, dan laporan penjualan.

\section{Beranda Menu}

Tampilan beranda merupakan tampilan utama dari aplikasi yang berisi informasi dasar dan menu atau fitur yang terdapat pada aplikasi. Bagian awal beranda dapat dilihat pada gambar 5 . 


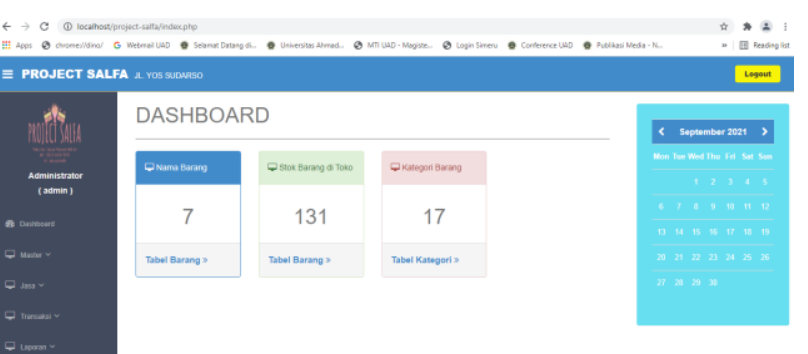

Gambar 5. Tampilan Beranda

\section{Form Pemesanan Jasa}

Form pemesanan jasa terdiri dari jasa dekorasi, pembuatan bucket, frame, selempang dan custom produk sesuai pesanan pelanggan. Contoh dari form pemesanan jasa dapat dilihat pada gambar 6.

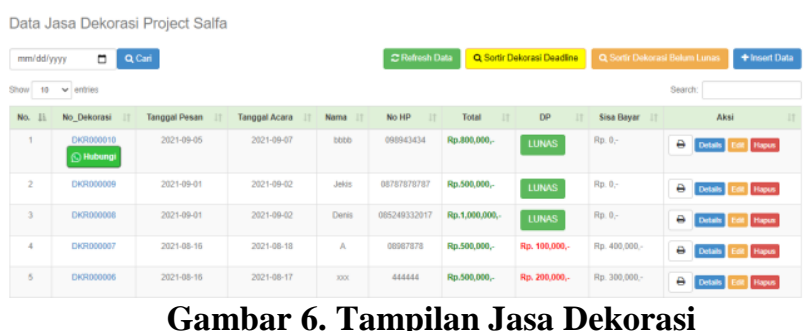

Pada dasarnya form dari pemesanan jasa ini hampir mirip dan cara kerjanya sama. Hanya saja perbedaan pada letak redaksi field menyesuaikan dari jenis pemesanan. User dapat melakukan filter data terkait pemesanan jasa seperti sortir pemesanan yang deadline dan pemesanan jasa yang belum lunas.

\section{Form Transaksi Penjualan}

Form transaksi penjualan merupakan inti dari aplikasi POS, dimana di form ini dilakukan transaksi penjualan terkait barang-barang yang dibeli oleh pelanggan. Form transaksi dapat dilihat pada gambar 7 .

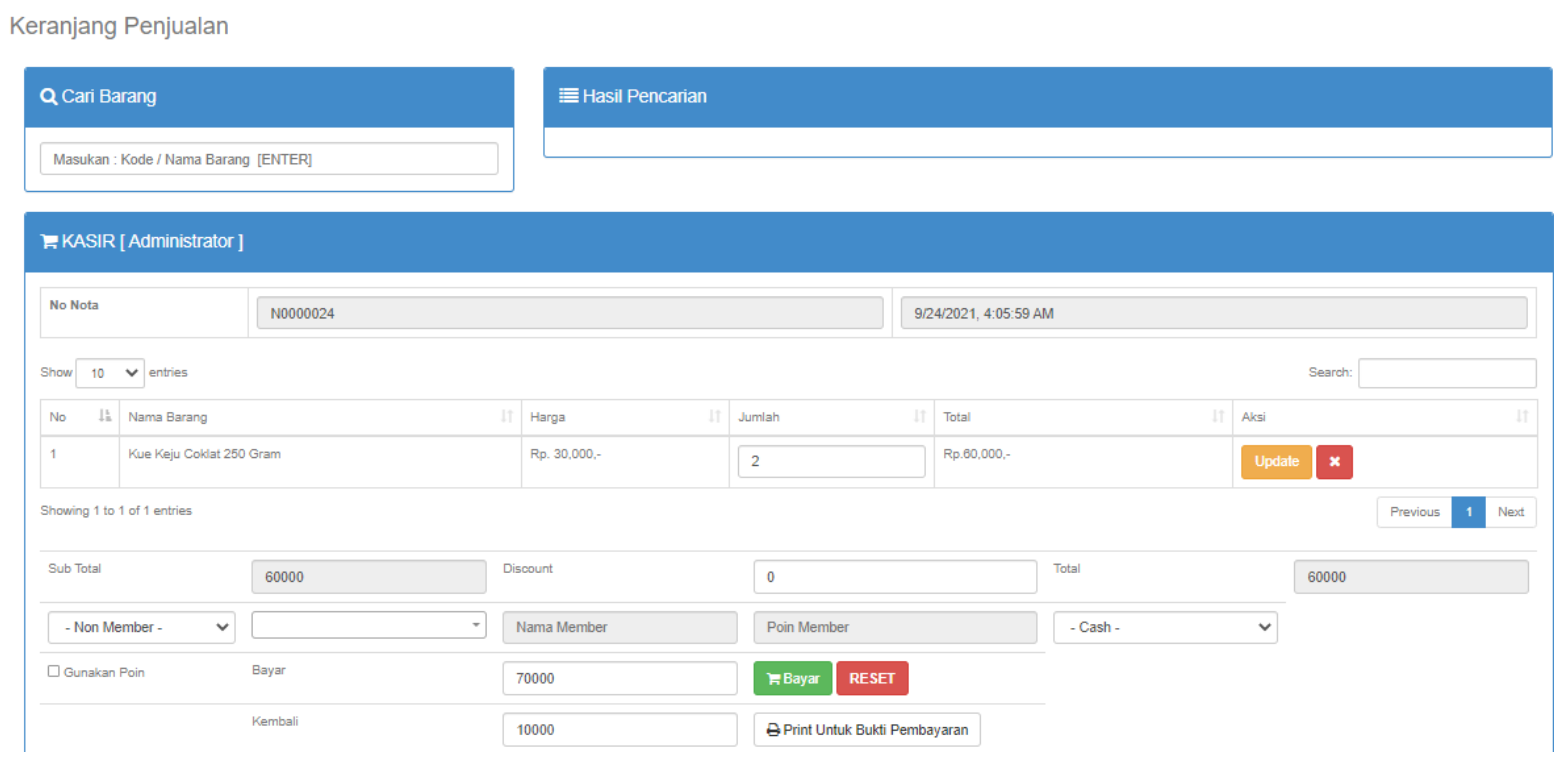

Gambar 7. Tampilan Form Transaksi Penjualan

Form ini terhubung dengan data barang seperti kode barang, nama barang serta harga dan stok. Selain itu form ini juga terhubung dengan data member dimana sistem penjualan juga menggunakan sistem member yang apabila pembelian dengan harga tertentu mendapatkan poin yang nantinya poin tersebut dapat digunakan untuk potongan harga.

Setiap transaksi penjualan yang terjadi dapat dilakukan dengan terlebih dahulu melakukan input kode barang melalui barcode scanner. Kemudian setelah transaksi selesai maka dapat mencetak nota melalui printer thermal sebagai bukti pembayaran.

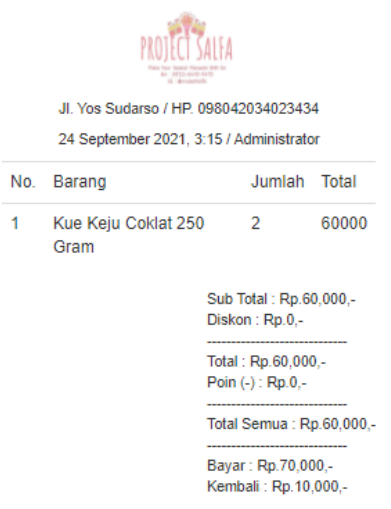

Terima Kasih Telah berbelanja di toko kami !

Gambar 8. Contoh Nota Penjualan 
Transaksi pemesanan jasa yang dimasukkan oleh kasir juga dapat mencetak nota pesanan sebagai bukti pengambilan pesanan.

5. Form Transaksi Pengeluaran

Transaksi pengeluaran merupakan fitur yang dibutuhkan pemilik untuk mencatat setiap pengeluaran toko seperti pembelian barang untuk modal, operasional dan lainnya. Berikut ini gambar 9 contoh dari transaksi pengeluaran.

\section{Data Pengeluaran Keuangan}

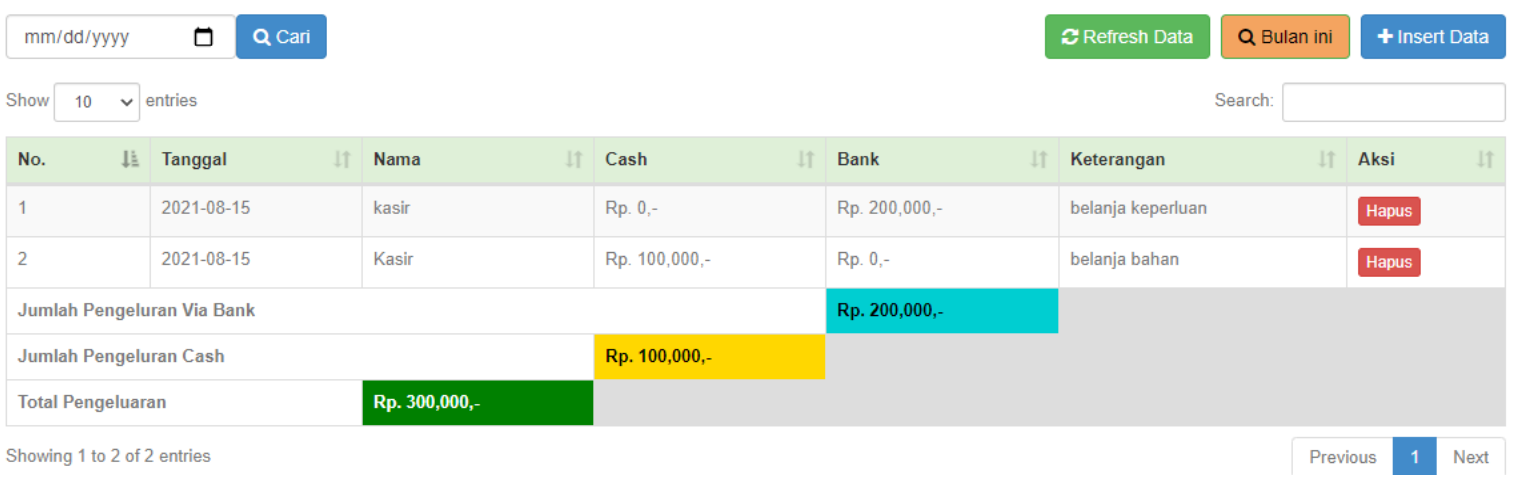

Gambar 9. Transaksi Penjualan

Transaksi ini memiliki dua tipe pengeluaran yaitu berbasis tunai dan transfer via bank. Setiap pengeluaran dicatat pada kolom yang berbeda agar memudahkan pemilik mengetahui mana yang pengeluaran tunai dan mana yang transfer.

6. Form Laporan Pemasukan

Form laporan memberikan informasi mengenai laporan pemasukan. Laporan pemasukan berasal dari transaksi penjualan serta dari transaksi dari pembayaran jasa seperti jasa dekorasi, penyewaan dan lainnya. Pencatatan laporan dari setiap transaksi berbasis tunai atau menggunakan sistem transfer via bank. Berikut ini gambar 10 laporan pemasukan.

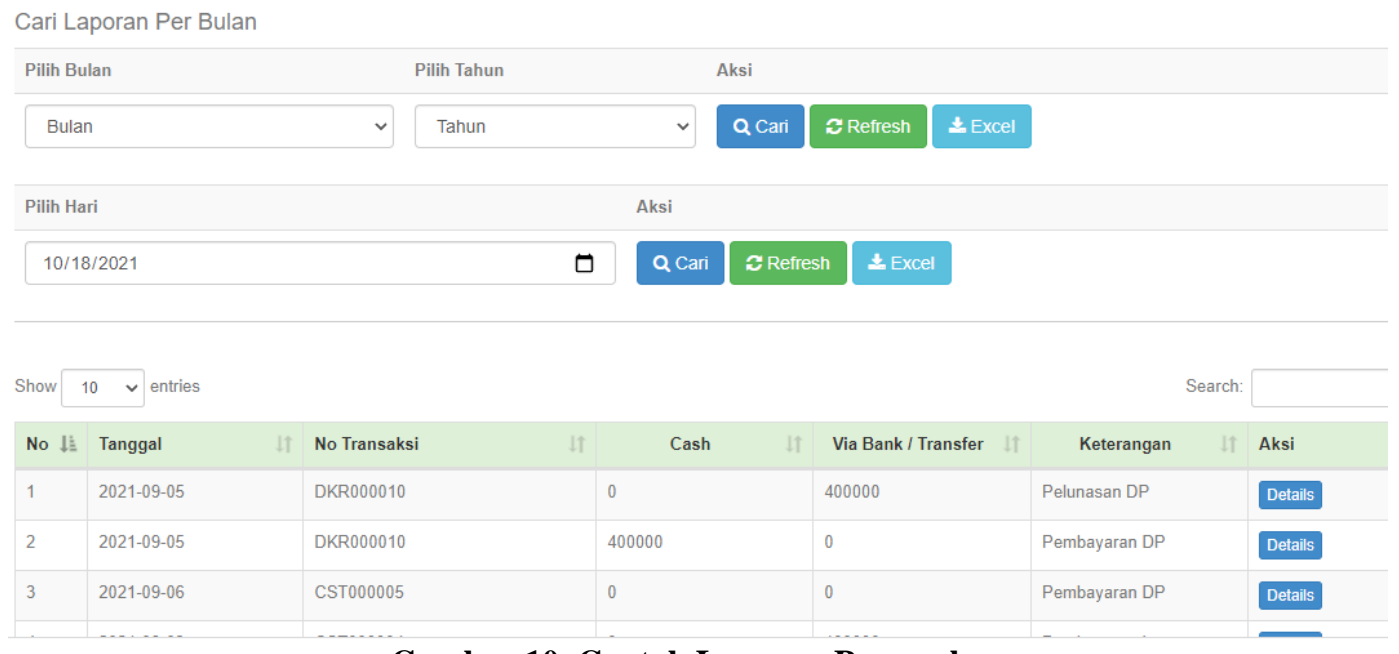

Gambar 10. Contoh Laporan Pemasukan

Gambar 10 merupakan contoh dari salah satu laporan dari transaksi dengan filter data per hari dan per bulan. Kemudian hasil filter dapat di export ke aplikasi excel atau dapat dicetak.

7. Form Laporan Omzet

Form laporan omzet dibutuhkan pemilik toko untuk mengetahui laporan omzet bruto yang didapat oleh toko setiap bulannya. Omzet didapat dari setiap pemasukan dari transaksi tunai dan transfer dari penjualan dan pemesanan jasa dan ditambah oleh modal bulan sebelumnya. Gambar 11 menampilkan contoh dari laporan omzet. 


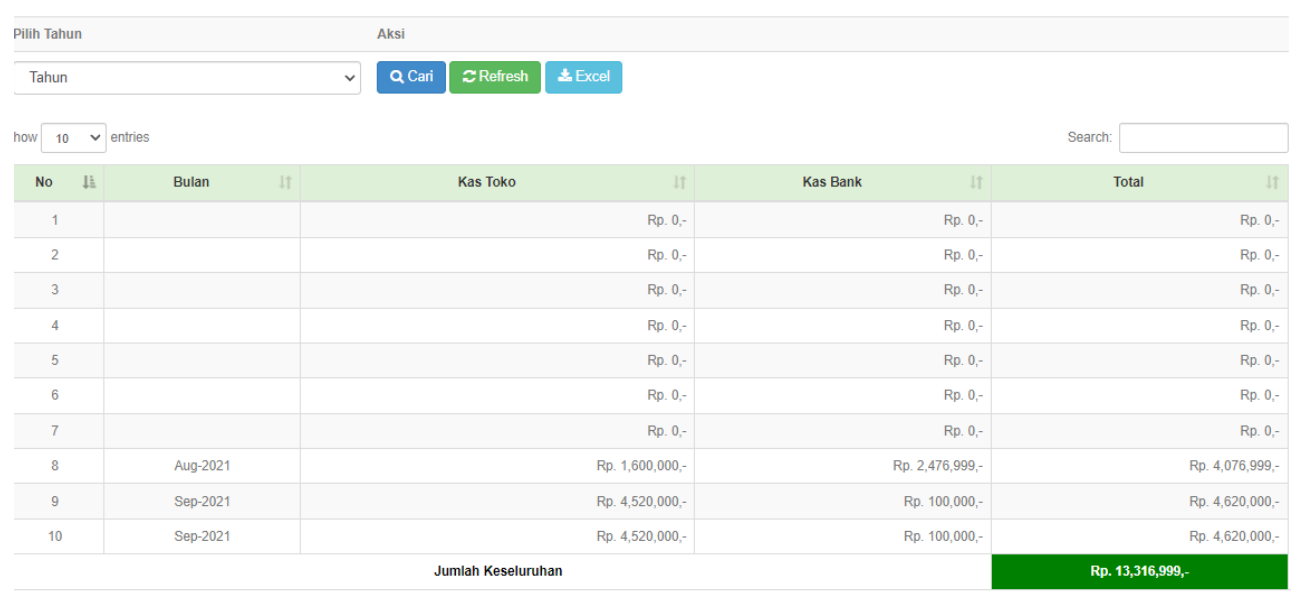

Gambar 11. Contoh Form Laporan Omzet

Laporan Omzet pada gambar 11 terlihat jumlah pemasukan setiap bulan dan jumlah modal sebelumnya. Untuk bulan januari hingga juli tidak ada pencatatan karena sistem POS belum tersedia.

\subsection{Integrasi dan Pengujian Sistem}

Pengujian integrasi merupakan teknik konstruksi untuk menguji kesalahan-kesalahan pada sistem setelah modul-modul yang terpisah digabungkan. Integrasi dilakukan dengan pendekatan hierarki top-down. Gambar 12 menunjukkan pengujian integrasi.

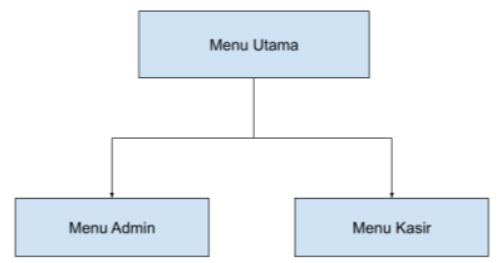

\section{Gambar 12. Pengujian Integrasi}

Pengujian sistem dilakukan untuk memastikan apakah aplikasi sudah berjalan dengan baik dan bekerja sesuai kebutuhan seperti desain, spesifikasi dan mengodekan. Penelitian ini menggunakan Black-box testing yang merupakan salah satu pengujian perangkat lunak dengan fokus pada persyaratan fungsional perangkat lunak. Adapun pengujian sistem menggunakan Black-box dapat dilihat pada tabel 3 berdasarkan rangkuman keseluruhan pengujian sistem dengan menggunakan akun level administrator dan kasir.
Tabel 3. Pengujian Menggunakan Black-box

\begin{tabular}{|c|c|c|}
\hline $\begin{array}{c}\text { Kasus } \\
\text { Pengujian } \\
\end{array}$ & Hasil yang Diharapkan & $\begin{array}{c}\text { Hasil } \\
\text { Pengujian } \\
\end{array}$ \\
\hline $\begin{array}{l}\text { Operasi CRUD } \\
\text { (Create, Read, } \\
\text { Update, Delete }) \\
\text { pada menu } \\
\text { master data }\end{array}$ & $\begin{array}{c}\text { Data berhasil } \\
\text { ditambahkan, tampil, } \\
\text { dapat diubah, dapat } \\
\text { dihapus pada setiap } \\
\text { menu di bagian master } \\
\text { data } \\
\text { Dengan level } \text { user } \\
\text { Administrator }\end{array}$ & $\begin{array}{l}\text { Sesuai } \\
\text { Harapan }\end{array}$ \\
\hline $\begin{array}{l}\text { Operasi CRUD } \\
\text { pada menu jasa }\end{array}$ & $\begin{array}{c}\text { Transaksi dapat } \\
\text { ditambahkan, } \\
\text { ditampilkan, diubah oleh } \\
\text { Administrator dan kasir. } \\
\text { Transaksi dapat dihapus } \\
\text { oleh Administrator }\end{array}$ & $\begin{array}{l}\text { Sesuai } \\
\text { Harapan }\end{array}$ \\
\hline $\begin{array}{l}\text { Operasi CRUD } \\
\text { pada menu } \\
\text { transaksi }\end{array}$ & $\begin{array}{c}\text { Transaksi dapat } \\
\text { ditambahkan, } \\
\text { ditampilkan, diubah oleh } \\
\text { Administrator dan kasir. } \\
\text { Transaksi dapat dihapus } \\
\text { oleh Administrator }\end{array}$ & $\begin{array}{l}\text { Sesuai } \\
\text { Harapan }\end{array}$ \\
\hline $\begin{array}{l}\text { Operasi CRUD } \\
\text { pada menu } \\
\text { laporan }\end{array}$ & $\begin{array}{l}\text { Laporan dapat dilihat } \\
\text { oleh administrator dan } \\
\text { kasir. } \\
\text { Laporan dapat dikoreksi } \\
\text { administrator } \\
\end{array}$ & $\begin{array}{l}\text { Sesuai } \\
\text { Harapan }\end{array}$ \\
\hline $\begin{array}{l}\text { Operasi CRUD } \\
\text { pada menu } \\
\text { pengaturan }\end{array}$ & $\begin{array}{l}\text { Manajemen toko dapat } \\
\text { diatur oleh administrator }\end{array}$ & $\begin{array}{l}\text { Sesuai } \\
\text { Harapan }\end{array}$ \\
\hline
\end{tabular}

\subsection{Operasional dan Perawatan}

Operasional dirancang agar dapat disesuaikan dan dioperasikan pada toko Project Salfa dengan melakukan instalasi terkait perangkat keras client-server dan perangkat lunak. Komputer client terpasang pada toko untuk transaksi penjualan, sedangkan komputer server berada pada ruangan khusus. Gambar 13 menunjukkan perancangan desain perangkat keras POS yang terhubung ke sistem. 


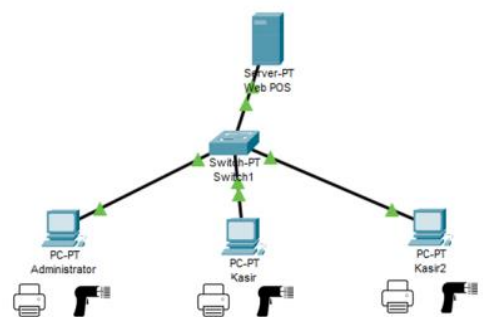

Gambar 13. Operasional Perangkat POS

\section{KESIMPULAN}

Perancangan aplikasi POS yang dibuat dapat membantu sistem transaksi yang selama ini dilakukan manual oleh pemilik toko sehingga memudahkan pekerjaan dalam menghitung stok, pemasukan, pengeluaran dan laba rugi. Aplikasi memungkinkan dapat diakses dari komputer lain apabila terhubung ke jaringan yang sama, dan dapat diakses dari luar jaringan yang berbeda apabila di Hosting. Aplikasi POS menggunakan $Q R$ code sebagai pendataan dan proses transaksi penjualan dan dapat terhubung dengan perangkat keras barcode scanner dan printer thermal dengan baik.

\section{SARAN}

Berdasarkan hasil penelitian ini, penulis memberikan saran berupa pengembangan aplikasi agar dapat digunakan oleh berbagai macam toko atau bidang yang bergerak pada sentra UMKM di kota Tarakan. Aplikasi sebaiknya juga dikembangkan agar dapat dijalankan pada smartphone, mengingat mobilitas yang lebih mudah pengakses bisa dimana saja sehingga transaksi pun bisa dilakukan kapan pun dan dimana pun tanpa harus berada di lokasi toko. Sistem pembayaran bisa dikembangkan dengan menambahkan fitur multi payment sehingga memudahkan pembayaran dari jarak jauh.

\section{DAFTAR PUSTAKA}

Afrianto, dkk. (2020). Sistem Informasi Inventory P.O.S (Point of Sales) Berbasis Web pada Counter Cellular. Jurteksi (Jurnal Teknologi Dan Sistem Informasi),6(2),125-134.

http://jurnal.stmikroyal.ac.id/index.php/jurteksi

Akhmad, K. A., \& Purnomo, S. (2021). Pengaruh Penerapan Teknologi Informasi Pada Usaha Mikro Kecil Dan Menengah Di Kota Surakarta. Sebatik, 25(1),234-240. https://doi.org/10.46984/sebatik.v25i1.1293

Alexander, J. (2020). Implementasi Point Of Sales Berbasis Web Pada Usaha Olive Café. Jusibi(Jurnal Sistem Informasi Dan E-Bisnis), 2(4), 452-465.

Ardiansyah, M. (2019). Analisis Dan Perancangan Sistem Informasi Point Of Sales Berbasis CRM. Jurnal Sistem Informasi, 8(1), 966-977.

Arman, M. (2019). Perbandingan Performansi Single Web Server Dan Multi Web Server Dengan Uji
Coba Paired Sample T Test. Jurnal Sisfokom (Sistem Informasi Dan Komputer), 8(2), 116-123. https://doi.org/10.32736/sisfokom.v8i2.668

Christian, Y. (2021). Perancangan Dan Penerapan Sistem Pos ( Point Of Sale) Berbasis Web Pada Warung Zikry. 1(1), 61-66.

Handrianto, Y., \& Sanjaya, B. (2020). Model Waterfall Dalam Rancang Bangun Sistem Informasi Pemesanan Produk Dan Outlet Berbasis Web. Jurnal Inovasi Informatika, 5(2), 153-160. https://doi.org/10.51170/jii.v5i2.66

Marisa, F., \& Yuarita, T. G. (2017). Perancangan Aplikasi Point of Sales (Pos) Berbasis Web Menggunakan Metode Siklus Hidup Pengembangan Sistem. Jurnal Teknologi Dan Manajemen Informatika, 3(2), 167-171. https://doi.org/10.26905/jtmi.v3i2.1514

Maulana, M. S. (2017). Rancangan dan Implementasi Aplikasi Web Point of Sales pada Butik Anak “ Galery Freya ." Jurnal Khatulistiwa Informatika, $V(1), 30-35$.

Nugraha, P. G. S. C. (2021). Rancang Bangun Sistem Informasi Software Point of Sale (Pos) Dengan Metode Waterfall Berbasis Web. JST (Jurnal Sains Dan Teknologi), 10(1), 92.

Pamungkas, G., \& Yuliansyah, H. (2017). Rancang Bangun Aplikasi Android Pos (Point of Sale) Kafe Untuk Kasir Portable Dan Bluetooth Printer. JST (Jurnal Sains Dan Teknologi), 6(1), 199-208. https://doi.org/10.23887/jst-undiksha.v6i1.8828

Subekti, dkk. (2019). Perancangan Infrastruktur Web Server Dan Database Menggunakan Metode Replication Mirror Dan Failover. Jurnal Cendikia, XVIII, 359-371.

Sugumonrong, dkk. (2019). Perancangan Sistem Informasi Point Of Sales (POS) Berbasis Web Pada Rumah Makan Kokobop Chicken. Journal Information System, 4(1).

Wahyudi, dkk. (2018). Aplikasi Penjualan Point of Sale (Pos) Menggunakan Barcode Pada Koperasi Bina Kasih Sejahtera Berbasis Desktop Dengan Metode First in First Out (Fifo). Jurnal Teknologi Informasi Dan Komputer, 3(2), 150-158.

Wiguna, dkk. (2019). Rancang Bangun Aplikasi Point of Sales Distro Management System dengan Menggunakan Framework React Native. Jurnal Nasional Teknologi Dan Sistem Informasi, 4(3), 149-159 